\title{
Dissolution kinetics of volatile organic compound vapors in water: An integrated experimental and computational study
}

\author{
Mojtaba G. Mahmoodlu ${ }^{\mathrm{a}, \mathrm{b}, *}$, Elizabeth M. Pontedeiro ${ }^{\mathrm{a}, \mathrm{c}}$, Jesús S. Pérez Guerrero ${ }^{\mathrm{d}}$, Amir Raoof ${ }^{\mathrm{a}}$, \\ S. Majid Hassanizadeh ${ }^{a}$, Martinus Th. van Genuchten ${ }^{\mathrm{a}, e}$ \\ a Department of Earth Sciences, Utrecht University, Utrecht, The Netherlands \\ b Department of Watershed and Rangeland Management, Gonbad Kavous University, Iran \\ c Department of Nuclear Engineering, Federal University of Rio de Janeiro, UFRJ, Rio de Janeiro, Brazil \\ d Radioactive Waste Division, Brazilian Nuclear Energy Commission, CNEN, Rio de Janeiro, Brazil \\ e NIDES Interdisciplinary Centr for Social Development, Federal University of Rio de Janeiro, UFRJ, Rio de Janeiro, Brazil
}

\section{A R T I C L E I N F O}

\section{Article history:}

Received 2 April 2016

Received in revised form 28 November 2016

Accepted 7 December 2016

Available online 10 December 2016

\section{Keywords:}

Volatile organic compounds

Dissolution

Kinetics

Molecular diffusion

Salinity

\begin{abstract}
A B S T R A C T
In this study we performed batch experiments to investigate the dissolution kinetics of trichloroethylene (TCE) and toluene vapors in water at room temperature and atmospheric pressure. The batch systems consisted of a water reservoir and a connected headspace, the latter containing a small glass cylinder filled with pure volatile organic compound (VOC). Results showed that air phase concentrations of both TCE and toluene increased relatively quickly to their maximum values and then became constant. We considered subsequent dissolution into both stirred and unstirred water reservoirs. Results of the stirred experiments showed a quick increase in the VOC concentrations with time up to their solubility limit in water. VOC vapor dissolution was found to be independent of $\mathrm{pH}$. In contrast, salinity had a significant effect on the solubility of TCE and toluene vapors. VOC evaporation and vapor dissolution in the stirred water reservoirs followed first-order rate processes. Observed data could be described well using both simplified analytical solutions, which decoupled the VOC dynamics in the air and water phases, as well as using more complete coupled solutions. However, the estimated evaporation $\left(k^{e}\right)$ and dissolution $\left(k^{d}\right)$ rate constants differed by up to $70 \%$ between the coupled and uncoupled formulations. We also numerically investigated the effects of fluid withdrawal from the small water reservoir due to sampling. While decoupling the VOC air and water phase mass transfer processes produced unreliable estimates of $k^{d}$, the effects of fluid withdrawal on the estimated rate constants were found to be less important. The unstirred experiments showed a much slower increase in the dissolved VOC concentrations versus time. Molecular diffusion of the VOCs within the aqueous phase became then the limiting factor for mass transfer from air to water. Fluid withdrawal during sampling likely caused some minor convection within the reservoir, which was simulated by increasing the apparent liquid diffusion coefficient.
\end{abstract}

(c) 2016 Elsevier B.V. All rights reserved.

\section{Introduction}

Possible contamination of soil and groundwater by volatile organic compounds (VOCs) is a major environmental concern at many sites currently or formerly occupied by large-scale chemical industries or smallscale users such as dry cleaners or gasoline stations (Han et al., 2016; Rivett et al., 2011; Schubert et al., 2011). VOCs frequently contaminate soil and groundwater and pose a potential threat to human health when migrating upward through the unsaturated soil to indoor air

\footnotetext{
* Corresponding author at: Department of Earth Sciences, Utrecht University, Utrecht, The Netherlands.

E-mail addresses: m.gharehmahmoodlu@uu.nl, m.g.mahmnoodlu@gmail.com (M.G. Mahmoodlu).
}

(Berscheid et al., 2010; Han et al., 2016; Mahmoodlu et al., 2013; Rivett et al., 2011).

Mass transfer of VOCs across air-water interfaces is a key process affecting the fate of VOCs in the environment, including their volatilization and partitioning into atmospheric water (Aumont et al., 2000; Boris et al., 2014; Ervens and Volkamer, 2010), as well as VOC removal from the unsaturated zone using various remediation techniques (Mahmoodlu et al., 2015; Schwarzenbach et al., 2003; Yap et al., 2012). Understanding the main factors affecting the dissolution of VOC into the water phase during their migration through the unsaturated zone is critical to optimizing subsurface remediation practices, as well as for developing predictive models of VOC reactive transport.

VOCs are generally hydrophobic and only slightly soluble in water (Görgényi et al., 2005; Peng et al., 2003). This can be a major hindrance to successful implementation of soil treatment technologies, which 
often target the dissolved mass of VOCs in the water phase. Low VOC dissolution rates lead to low conversion rates and hence longer treatment times and higher remediation costs (Chawla et al., 2001). Having accurate data about VOC dissolution processes into water under different conditions is for these reasons essential to foresee the potential of enhanced soil and groundwater remediation techniques (Yap et al., 2012).

The effects of selected chemical properties of the water phase, most notably salinity, on mass transfer of residual VOCs in the subsurface have been widely studied. Several studies have shown that salinity can decrease the solubility of VOC in water (Endo et al., 2012; Falabella and Teja, 2008; Görgényi et al., 2005; Schwarzenbach et al., 2003; USEPA, 1991). The presence of dissolved electrolytes, in particular small ions, increases the structuring of aqueous phases and thus the cohesive energy in the water phase (Bowen and Yousef, 2003; Endo et al., 2012). Salinity can also cause a shift in the equilibrium partitioning of neutral organic solutes toward non-aqueous phases. This effect is sometimes referred to as the salting-out effect (Endo et al., 2012). The literature shows that all gasoline components are salted out by sodium chloride such that they become less soluble in saline solutions than in pure water (e.g., Falabella and Teja, 2008). This can lower the removal efficiency of remediation methods. Furthermore, as a result of saltingout effects, Henry's constants of VOCs in saline water decrease. Several soil and groundwater remediation methods for removing VOC vapors, such as air stripping and soil vapor extraction, depend on having reliable estimates of Henry's constant (Falabella and Teja, 2008; Vane and Giroux, 2000). This requires knowledge of the partitioning behavior of VOCs between the air and water phases.

Current literature lacks information about the dissolution kinetics of VOC vapors into water and the different factors that may affect VOC partitioning between the air and water phases. Moreover, many or most reactive transport models assume that mass transfer across airwater interfaces is an equilibrium process governed by Henry's law. This assumption does not always hold. For example, Sleep and Sykes (1989) reported that at many sites where VOC vapors were present as an immiscible phase, VOC concentrations in the water phase were not consistent with equilibrium concentrations. Hence, it remains unclear how kinetic processes and other factors such as molecular diffusion of VOCs do affect the mass transfer of VOC vapors across air-water interfaces. To address this problem, we performed a series of batch experiments to more closely investigate VOC vapor dissolution and subsequent diffusion into the liquid phase. Specific objectives of our study were to (1) estimate the kinetics of VOC vapor dissolution (TCE and toluene in this study) into a stirred water reservoir, (2) investigate the effect of chemical properties of the water phase such as $\mathrm{pH}$ and especially salinity on VOC vapor dissolution in water, (3) evaluate the effect of molecular diffusion in water on VOC mass transfer across the air-water interface, and (4) numerically simulate VOC vapor dissolution and transport within the aqueous phase.

\section{Materials and methods}

\subsection{Experimental setup and procedure}

The chemicals used in this study were pure TCE and toluene (obtained from Sigma-Aldrich and Merck, respectively), and mercury chloride $\left(\mathrm{HgCl}_{2}\right)$ of $99.5 \%$ purity (Sigma-Aldrich). Fig. 1 shows a schematic of our experimental setup. The system consisted of a glass cylinder (column) of $5.0 \mathrm{~cm}$ length and $4.0 \mathrm{~cm}$ internal diameter, together with a very small glass cylinder hanging in the middle of the larger container. The larger cylinder had three ports capped by stainless steel lids. We first introduced $24.5 \mathrm{ml}$ deionized (DI) water into the column via the lower water sampling port which was located $0.8 \mathrm{~cm}$ from the bottom of the column. Next, $0.5 \mathrm{ml}$ mercury chloride of $10 \mathrm{mg} \mathrm{l}^{-1}$ was added to the water pool to suppress any microorganism activity within the setup, thus eliminating possible biodegradation processes during the

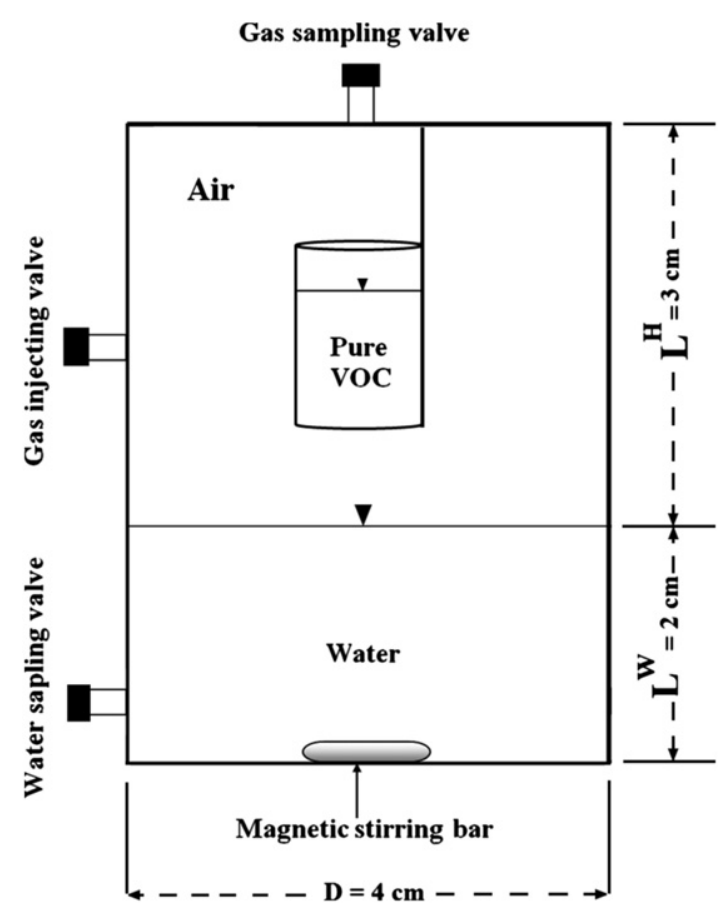

Fig. 1. Schematic view of the experimental setup. $L^{H}$ is the height of headspace, $L^{W}$ the height of water reservoir, and $D$ is the inner diameter of container.

experiments. Water inside the column was subsequently mixed thoroughly using a magnetic stirring bar (SCILOGEX PTFE, with pivot ring, $25 \times 7.9 \mathrm{~mm}$ ) and a magnetic stirrer (IKA, Germany) to obtain a homogenous solution of DI water and the mercury chloride. We next introduced $2.0 \mathrm{ml}$ of pure phase VOC into the small hanging glass cylinder in the headspace (Fig. 1), after which the top of the column was capped immediately with a vapor-tight stainless steel lid.

Several batch experiments were conducted to determine the evaporation rate constants $\left(k^{e}\right)$ of TCE and toluene from the small hanging VOC container into the headspace, and the dissolution rate constant $\left(k^{d}\right)$ describing subsequent dissolution kinetics of the VOC vapors from the headspace into the water phase. For the stirred experiments we used the magnetic stirrer to eliminate any VOC diffusion gradients within the water phase, thus ensuring uniform concentrations within the water reservoir. Precautions were taken not to disturb the airwater interface. We also performed batch experiments without stirring the water phase to evaluate the effect of VOC diffusion within the water phase on mass transfer, and hence the dissolution rate. To investigate the effects of salinity on VOC dissolution, an experiment was conducted (while again stirring) using seawater with a salinity of $0.6 \mathrm{M}$. Additional experiments for each compound were performed with a $\mathrm{pH}$ buffer to determine the effect of $\mathrm{pH}$ on the dissolution kinetics of the two VOC vapors in water. The buffer solution was prepared using $\mathrm{HCl}$ and $\mathrm{NaOH}$ of $1 \mathrm{M}$. We assumed that the temperature and pressure inside the batches were constant and remained at room temperature $\left(21 \pm 1{ }^{\circ} \mathrm{C}\right)$ and atmospheric pressure, respectively. In all experiments, the volume of VOC liquid was large enough so that it did not deplete during the full duration of the experiments. All experiments were carried out in duplicate (Exp. 1 and 2 in this study represent the two replicates of the VOC experiments).

\subsection{Sampling and measurements}

We measured VOC concentrations of both the gas and water phases during the stirred and unstirred experiments. Gas samples of $1.5 \mathrm{ml}$ were periodically taken from the headspace of the column using a $2.5 \mathrm{ml}$ gas-tight syringe (SGE Analytical Science, Australia). To avoid a drop in air pressure due to sampling, the same volume of air $(1.5 \mathrm{ml})$ 


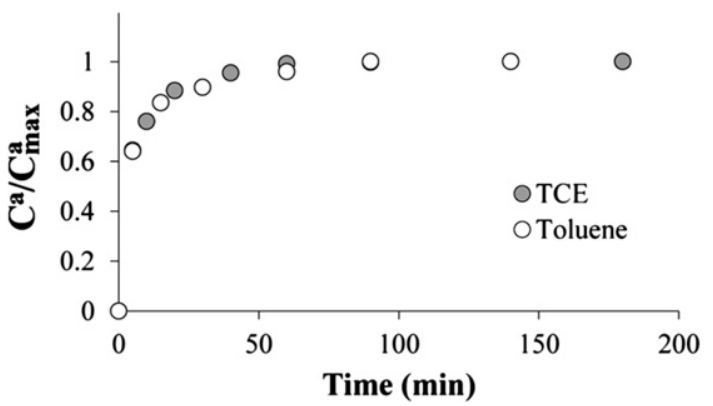

Fig. 2. Observed concentrations of TCE and toluene in the air phase.

was simultaneously injected into the upper part of the column through a separate port (Fig. 1). The VOC gas samples were injected into $10-\mathrm{ml}$ transparent glass vials, which were sealed with a magnetic cap and hard septum (Magnetic Bitemall; Grace Alltech). We periodically also took aqueous samples of $1.5 \mathrm{ml}$ each via the water sampling port using a $2.5 \mathrm{ml}$ gas-tight syringe. We then injected simultaneously the same volume of air ( $1.5 \mathrm{ml})$ into the headspace through the separate injection port, again to avoid any air pressure changes. The aqueous samples were inserted into $10-\mathrm{ml}$ transparent glass vials and sealed with a magnetic cap and hard septum.

Sampling vials were immediately placed into the tray of a gas chromatograph (GC). Gas samples of $2.0 \mathrm{ml}$ were taken from each vial with an autosampler using the headspace syringe of the GC. Samples were next injected into the GC. The GC (Agilent 6850) we used was equipped with a flame ionization detector. Separation was done on an Agilent HP1 capillary column (stationery phase: 100\% dimethylpolysiloxane, length: $30 \mathrm{~m}$, ID: $0.32 \mathrm{~mm}$, film thickness: $0.25 \mu \mathrm{m}$ ). A temperature programmed run was used to analyze the samples. VOC concentrations were determined using a headspace method as employed in previous studies (e.g. Almeida and Boas, 2004; Przyjazny and Kokosa, 2002; Sieg et al., 2008; Snow, 2002). The limits of quantification were calculated by using a signal-to-noise ratio of 10:1 (Kubinec et al., 2005).

\section{Processes and governing mass transfer equations}

As shown in Fig. 1, our experimental setup contained three domains. The first domain consisted of a water pool (reservoir) at the bottom of the column. The second domain comprised the air space above the water reservoir. The third domain was a pool of the particular VOC inside a small hanging glass container in the middle of air space. From the moment the pure VOC was placed in the hanging glass container, the following processes took place in the column: (1) evaporation of the VOC from the small liquid pool into the closed air space, (2) diffusion of VOC vapor within the air space, and (3) dissolution of VOC vapor into the water reservoir. We assumed that the air pressure and temperature did not change during the experiments. Our analysis also assumed that diffusion in air was fast enough so that a uniform concentration in the headspace could be assumed. We describe separately the governing equations for the experiments with the stirred and unstirred water reservoirs, as well as provide several exact and approximate analytical and numerical solutions that were for optimal analysis of the data.

\subsection{Governing equations for the stirred experiments}

The governing equations for the VOC concentrations in the headspace and the water reservoir (Mahmoodlu et al., 2014, 2015; Schwarzenbach et al., 2003; Yoshii et al., 2012) can be written as:

$V^{a} \frac{d C^{a}}{d t}=A^{a p} k^{e}\left(C_{\max }^{a}-C^{a}\right)-A^{a w} k^{d}\left(\frac{C^{a}}{H_{c}}-C^{w}\right)$

$V^{w} \frac{d C^{w}}{d t}=A^{a w} k^{d}\left(\frac{C^{a}}{H_{c}}-C^{w}\right)$

where $C^{a}$ and $C^{w}$ are the VOC concentrations of the head air space and the water reservoir, respectively $\left[\mathrm{ML}^{-3}\right], t$ is time [T], $C_{\max }^{a}$ is the maximum headspace concentration, corresponding to the VOC vapor pressure [ $\mathrm{MT}^{-1}$ ], $V^{a}$ and $V^{w}$ are the volumes of the headspace and stirred water reservoir, respectively $\left[\mathrm{L}^{3}\right], k^{e}$ denotes the apparent rate coefficient for evaporation from the VOC pool into the headspace [ $\left.\mathrm{LT}^{-1}\right]$, $A^{a p}$ is the surface area of the pure VOC reservoir in the internal cylinder of the headspace $\left[\mathrm{L}^{2}\right], A^{a w}$ is the surface area of the air-water interface between the headspace and the water reservoir $\left[\mathrm{L}^{2}\right]$, and $k^{d}$ is rate coefficient for VOC dissolution into the stirred water phase [ $\left.\mathrm{LT}^{-1}\right]$.

As mentioned above, we assumed that the headspace is a wellmixed reservoir throughout which the evaporated VOCs are distributed instantaneously and uniformly. This assumption can be made in view of the relatively large diffusion coefficients of VOCs in free air (about $5 \times 10^{-4} \mathrm{~cm}^{2} \mathrm{~min}^{-1}$ ) and the small volume of the headspace (less than $40 \mathrm{~cm}^{3}$ ). Since diffusion within the water phase was eliminated by stirring, VOC concentrations can be assumed to be uniform also within the water reservoir. Eqs. (1) and (2) further assume that both VOC evaporation into the headspace and subsequent dissolution into the water reservoir can be modeled as linear kinetic processes (Schwarzenbach et al., 2003; Yoshii et al., 2012). They were solved subject to zero initial concentrations in both the headspace and water reservoir. Below we present both approximate and exact solutions of the model for a stirred reservoir, as well as a more comprehensive formulation and numerical solution for an unstirred reservoir, in which case diffusive transport is considered from the air-water interface into the liquid phase. We further provide an analysis of the possible effects of fluid withdraw during sampling on the results.

\subsection{Approximate solution for the stirred experiments}

Our experimental results (Fig. 2) showed that VOC concentrations in the headspace reached their maximum values $\left(C_{\max }^{a}\right)$ relatively quickly (mostly within $50 \mathrm{~min}$ ), whereas mass transfer across the air-water interface took place over much longer time periods before equilibrium
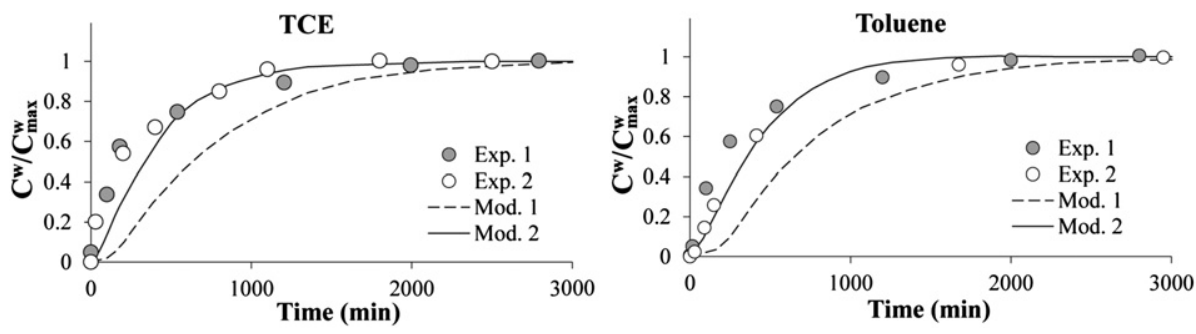

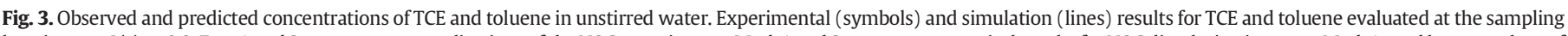

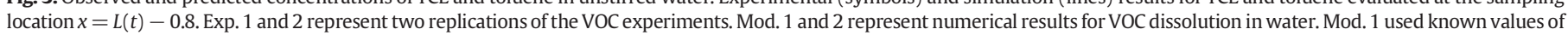
the VOC molecular diffusion coefficient in water (Table 1), whereas Mod. 2 used diffusion coefficients that were increased by a factor of three. 
was reached within the water reservoir. One can take advantage of this by decoupling Eq. (2) from Eq. (1) to produce a separate independent equation for $C^{w}$ of the form (Mahmoodlu et al., 2014, 2015; Schwarzenbach et al., 2003; Yoshii et al., 2012)

$V^{w} \frac{d C^{w}}{d t}=A^{a w} k^{d}\left(C_{\max }^{w}-C^{w}\right)$

where

$C_{\max }^{w}=S^{w}=C_{\max }^{a} / H_{c}$

Eq. (3) can be solved readily to give

$\frac{C^{w}(t)}{S^{w}}=1-\exp \left(-\frac{A^{a w} k^{d} t}{V^{w}}\right)$

or equivalently

$\ln \left[\frac{S^{w}-C^{w}(t)}{S^{w}}\right]=-\frac{A^{a w} k^{d} t}{V^{w}}$

Eq. (5b) shows that the dissolution rate coefficient $\left(k^{d}\right)$ can be estimated immediately from the slope of a straight line between $\ln \left[\left(S^{w}-C^{w}\right) / S^{w}\right]$ versus $t$.

\subsection{Exact solution for the stirred experiments}

While approximate, the above solution should provide a useful description of the VOC dissolution process. More precise solutions are possible by directly solving Eqs. (1) and (2) simultaneously subject to zero initial concentrations for $C^{a}$ and $C^{w}$. We obtained the following exact solutions for the coupled set of equations:

$\frac{C^{a}(t)}{C_{\max }^{a}}=1-\frac{\left(a_{2}+a_{3}\right)}{2 a_{3}} \exp \left[-\frac{\left(a_{1}-a_{3}\right)}{2 a_{4}} t\right]-\frac{\left(a_{3}-a_{2}\right)}{2 a_{3}} \exp \left[-\frac{\left(a_{1}+a_{3}\right)}{2 a_{4}} t\right]$

$\frac{C^{w}(t)}{C_{\max }^{w}}=1-\frac{\left(a_{1}+a_{3}\right)}{2 a_{3}} \exp \left[-\frac{\left(a_{1}-a_{3}\right)}{2 a_{4}} t\right]-\frac{\left(a_{3}-a_{1}\right)}{2 a_{3}} \exp \left[-\frac{\left(a_{1}+a_{3}\right)}{2 a_{4}} t\right]$

where

$a_{1}=A^{a w}\left(H_{c} V^{a}+V^{w}\right) k^{d}+A^{a p} H_{c} V^{w} k^{e}$

$a_{2}=A^{a w}\left(H_{c} V^{a}+V^{w}\right) k^{d}-A^{a p} H_{c} V^{w} k^{e}$

$a_{3}=\sqrt{\left[A^{a p} H_{c} V^{w} k^{e}+A^{a w}\left(H_{c} V^{a}+V^{w}\right) k^{d}\right]^{2}-4 A^{a p} A^{a w} H_{c}^{2} V^{a} V^{w} k^{e} k^{d}}$

$a_{4}=H_{c} V^{a} V^{w}$

Eqs. (6) to (7) will be used to verify the appropriateness of decoupling Eqs. (1) and (2) and using the independent Eq. (5b) for estimating the rate coefficient $k^{d}$ from semi-logarithmic plots of the VOC fluid concentration versus time.

\subsection{Effects of fluid withdrawal during sampling}

Repeated sampling from the relatively small volume of the water reservoir caused the water level to decrease slowly but appreciably during the experiments. We investigated the significance of these fluid withdrawals by adjusting the above solutions for the withdrawals. An approximate way would be to simply adjust the values of $V^{w}$ as a function of time in Eqs. (5a) and (5b) to correct for the sampling. For
Table 1

Experimental conditions and input parameters for the VOC simulations.

\begin{tabular}{|c|c|c|c|}
\hline Parameters & VOC & Value & Reference \\
\hline Length of column $(\mathrm{cm})$ & - & 5.0 & - \\
\hline Internal diameter of column $(\mathrm{cm})$ & - & 4.0 & - \\
\hline $\begin{array}{l}\text { Initial volume of water in column, } V^{w} \\
\left(\mathrm{~cm}^{3}\right)\end{array}$ & - & 25.0 & - \\
\hline Initial volume of air in column, $V^{a}\left(\mathrm{~cm}^{3}\right)$ & - & 37.8 & - \\
\hline Air-water surface area, $A^{a w}\left(\mathrm{~cm}^{2}\right)$ & - & 12.56 & - \\
\hline Length of VOC container $(\mathrm{cm})$ & - & 2.0 & - \\
\hline Internal diameter of VOC container $(\mathrm{cm})$ & - & 1.5 & - \\
\hline $\begin{array}{l}\text { Initial volume of VOC pool in container, } \\
V^{p}\left(\mathrm{~cm}^{3}\right)\end{array}$ & - & 2.0 & - \\
\hline Air-VOC pool surface, $A^{a p}\left(\mathrm{~cm}^{2}\right)$ & - & 1.767 & - \\
\hline \multirow{2}{*}{$\begin{array}{l}\text { Henry's Law constant for water at } 20{ }^{\circ} \mathrm{C} \text {, } \\
H_{C}(-)\end{array}$} & TCE & 0.42 & - \\
\hline & Toluene & 0.358 & - \\
\hline \multirow{2}{*}{$\begin{array}{l}\text { Henry's Law constant for sea water at } \\
20{ }^{\circ} \mathrm{C}(-)\end{array}$} & TCE & 0.28 & - \\
\hline & Toluene & 0.19 & - \\
\hline \multirow[t]{2}{*}{ VOC solubility in seawater } & TCE & $8.5 \times 10^{-4}$ & - \\
\hline & Toluene & $3.4 \times 10^{-4}$ & - \\
\hline \multirow{2}{*}{$\begin{array}{l}\text { Maximum VOC concentration in air, } C_{\max }^{a} \\
\left(\mathrm{~g} \mathrm{~cm}^{-3}\right)\end{array}$} & TCE & $4.93 \times 10^{-4}$ & - \\
\hline & Toluene & $1.71 \times 10^{-4}$ & - \\
\hline \multirow{2}{*}{$\begin{array}{l}\text { Maximum VOC concentration in water, } \\
C_{\max }^{w}\left(\mathrm{~g} \mathrm{~cm}^{-3}\right)\end{array}$} & TCE & $1.15 \times 10^{-3}$ & - \\
\hline & Toluene & $4.79 \times 10^{-4}$ & - \\
\hline \multirow[t]{2}{*}{$\begin{array}{l}\text { Molecular diffusion coefficient in air, } D^{a} \\
\left(\mathrm{~cm}^{2} \min ^{-1}\right)\end{array}$} & TCE & 4.74 & $\begin{array}{l}\text { Estivill et al. } \\
\text { (2007) }\end{array}$ \\
\hline & Toluene & 5.22 & $\begin{array}{l}\text { Hers et al. } \\
(2000)\end{array}$ \\
\hline \multirow[t]{2}{*}{$\begin{array}{l}\text { Molecular diffusion coefficient in water, } \\
D^{w}\left(\mathrm{~cm}^{2} \mathrm{~min}^{-1}\right)\end{array}$} & TCE & $5.4 \times 10^{-4}$ & $\begin{array}{l}\text { Lewis et al. } \\
\text { (2009) }\end{array}$ \\
\hline & Toluene & $5.1 \times 10^{-4}$ & $\begin{array}{l}\text { Hers et al. } \\
(2000)\end{array}$ \\
\hline
\end{tabular}

example, in several experiments $1.5-\mathrm{ml}$ sampling fluid was withdrawn at various times, leading to following expression for $V^{w}(t)$

$V^{w}(t)= \begin{cases}25.0 & 0 \leq t \leq 5 \\ 23.5 & 5<t \leq 10 \\ 22.0 & 10<t \leq 20 \\ 20.5 & 20<t \leq 40 \\ 19.0 & 40<t \leq 60 \\ 17.5 & 60<t \leq 90 \\ 16.0 & t>90\end{cases}$

where $V_{w}(t)$ is given in $\mathrm{ml}$ and $t$ in mins. Fluid sampling hence took place at times $t=5,10,20,40,60$ and 90 mins from the water sampling port located $0.8 \mathrm{~cm}$ from the bottom of cylinder. As a first approximation we hence simply employed Eq. (5a) again but now accounting for fluid phase sampling by considering $V_{w}$ as functions of time as given by Eq. (9), consistent with the invoked sampling protocols, i.e.,

$\frac{C^{w}(t)}{S^{w}}=1-\exp \left(-\frac{A^{a w} k^{d} t}{V^{w}(t)}\right)$

The accuracy of the decoupled Eqs. (5a), (5b) and (10) for estimating $k^{d}$ was tested by comparing results with complete coupled exact and

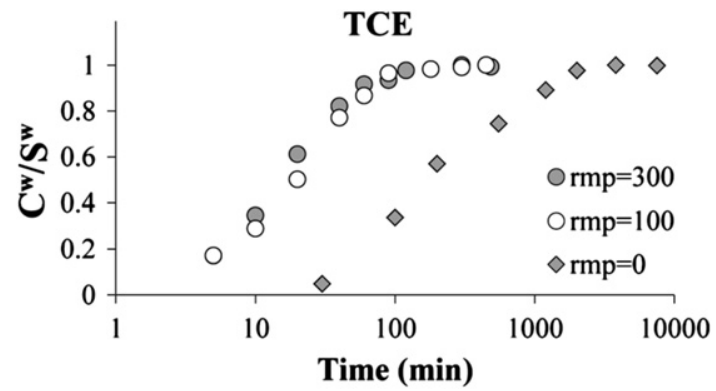

Fig. 4. Effect of stirring speed (rpm) on the dissolution rate of TCE into water (rpm indicates the number of revolutions per minute). 

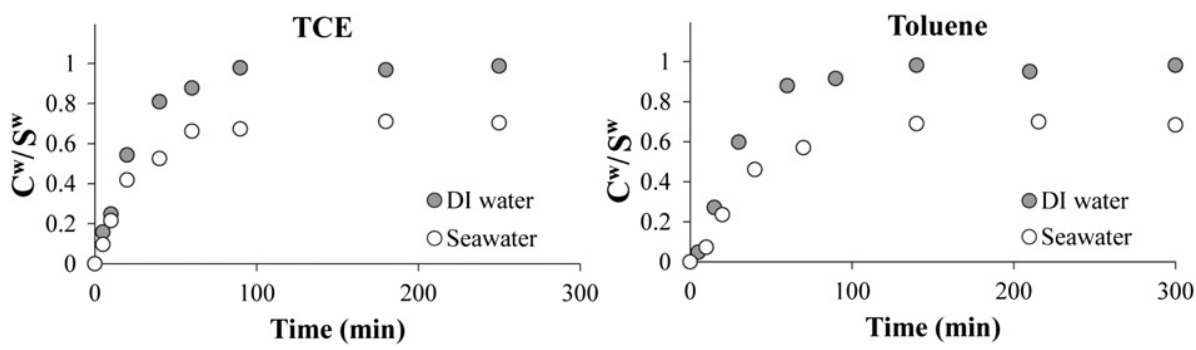

Fig. 5. Salinity effects on the dissolution and solubility of TCE and toluene in stirred water.

numerical solutions of Eqs. (1) and (2) subject to constant and timevarying values of $V^{a}$ and $V^{w}$ values. We note that the removed sampling fluid always contained some dissolved VOCs, which hence constituted a small sink in the governing mass balance equation. This removal of VOC is actually accounted for automatically in the governing equation for the VOC fluid reservoir, given by Eq. (2), by keeping $V^{w}(t)$ outside of the time derivative.

\subsection{Governing equations for the unstirred experiments}

The rate of VOC diffusion into the water reservoir was followed by taking small samples from the sampling port located $0.8 \mathrm{~cm}$ above the bottom of the water reservoir. The resulting problem can be approximated as one-dimensional diffusion problem. Similarly to the stirred experiments, the water level $(L)$ of the liquid reservoir during the unstirred experiments decreased significantly: from about $2.0 \mathrm{~cm}$ at $t=0$ to about $1.5 \mathrm{~cm}$ at $t=4000 \mathrm{~min}$. To account for the fluid withdrawal, the resulting diffusion problem was modeled as a moving boundary value problem using the equation

$\frac{\partial C^{w}(x, t)}{\partial t}=D^{w} \frac{\partial^{2} C(x, t)}{\partial x^{2}} \quad 0 \leq x \leq L(t)$

where $x$ is distance from the water level downwards, $D_{A}^{w}$ is the molecular diffusion coefficient of the VOC in water, and $L(t)$ is the length (height) of the liquid reservoir, being initially at $L_{0}=L(0)$, but slowly decreasing as a function of time. The height of the reservoir could be described in the same form as Eq. (9), except for different sampling times (up to about 4500 min as shown in Fig. 3).

Eq. (11) was solved subject to a zero initial concentration, i.e.,

$C^{w}(x, t=0)=0 \quad 0 \leq x \leq L(t)$

Since the VOC concentration in the air phase reached its equilibrium value relatively quickly, the simplest boundary condition at the airwater surface $(x=0)$ is a Dirichlet type condition of the form

$C^{w}(x=0, t)=C_{\max }^{w}\left(1-e^{\mu t}\right)$

which relates the boundary fluid concentration to the air phase VOC concentration using Henry's law (Eq. (4)). The exponential term in
Eq. (13) may be used to account for increased air phase VOC concentrations during the early part of the experiments. For the fully decoupled scenario without considering mass transfer across the air-water interface, the value of $\mu$ then follows from the exact solution of Eq. (1), without the last (third) term, to give $\mu=A^{p} k^{e} / V^{a}$.

At the lower boundary $L(t)$ of the finite experimental setup we further have a no-flux boundary condition given by

$\frac{\partial C^{w}(x=L(t), t)}{\partial x}=0$

Since solute is withdrawn at the same time as the value of $L(t)$ is changed, the local concentration in the reservoir at the sampling point should change little or not at all, provided convective mixing due to fluid withdrawal is minimized during sampling. Since sampling took place from inside the water reservoir (roughly from the middle of the reservoir), the local concentrations immediately above and below the sampling point would become briefly discontinuous after fluid withdrawal. If the sampling had been conducted at the very bottom of the liquid reservoir, no such discontinuity would have occurred. Our modeling approach hence assumes that the slow withdrawal of fluid due to sampling will not affect the concentration distribution within the water reservoir, with the lower boundary slowly moving upward.

The resulting diffusion problem with a moving boundary condition is described by Eqs. (11) through (14), with $L(t)$ given by Eq. (9) or a similar discontinuous equation versus time. The problem can be redefined into an equivalent set of equations with a fixed boundary condition using a change of variable as follows:

$\xi=\frac{x}{L(t)}$

leading to the set of equations

$\frac{\partial C^{w}(\xi, t)}{\partial t}=\frac{D_{A}^{w}}{L^{2}(t)} \frac{\partial^{2} C^{w}(x, t)}{\partial \xi^{2}}+\frac{\xi}{L(t)} \frac{d L(t)}{d t} \frac{\partial C^{w}(x, t)}{\partial \xi}$

$C^{w}(\xi, t=0)=0$

$C^{w}(\xi=0, t)=C_{0}^{w}\left(1-e^{\mu t}\right)$

\section{$V^{\mathbf{w}}$ constant with time}

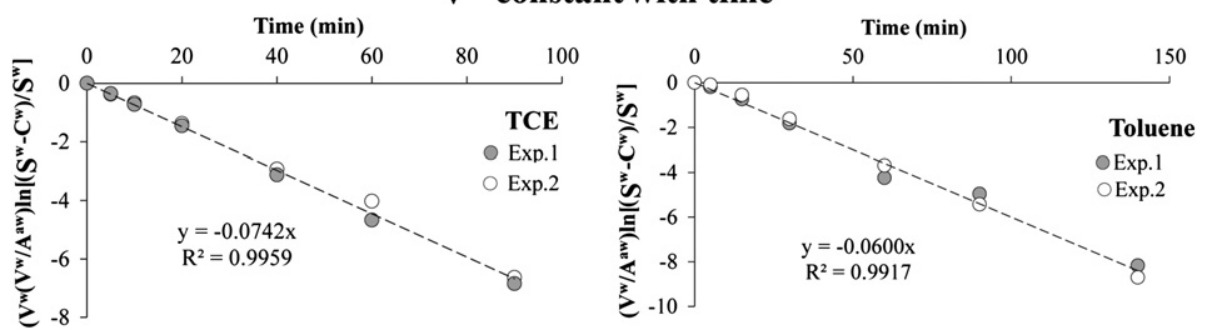

Fig. 6. Plots of $V^{w} / A^{a w} \ln \left[\left(S^{w}-C^{w}\right) / S^{w}\right]$ vs. time corresponding to Eqs. (5a) and (5b) assuming constant values of $V^{a}$ and $V^{w}$. 
Table 2

Estimated dissolution rate coefficients $\left(k^{d}\right)$ for the stirred experiments without (AD) and with (AD-W) accounting for fluid withdrawal during sampling, and estimated evaporation $\left(k^{e}\right)$ and dissolution $\left(k^{d}\right)$ rate coefficients for the coupled models for the unstirred experiments without (EC) and with (NC-W) fluid withdrawal.

\begin{tabular}{lllll}
\hline Model & Description & VOC & $\begin{array}{l}k^{e} \\
\left.(\mathrm{~cm} \mathrm{~min})^{-1}\right)\end{array}$ & $\begin{array}{l}k^{d} \\
\left.(\mathrm{~cm} \mathrm{~min})^{-1}\right)\end{array}$ \\
\hline \multirow{2}{*}{ AD } & Approximate decoupled solution, & TCE & - & 0.074 \\
& Eqs. (5a) and (5b) & Toluene & - & 0.060 \\
\multirow{2}{*}{ AD-W } & Approximate decoupled solution & TCE & - & 0.055 \\
& with fluid withdrawal; Eq. (10) & Toluene & - & 0.044 \\
EC & Exact coupled solution, Eqs. (6) & TCE & 5.7 & 0.121 \\
& and (7) & Toluene & 5.2 & 0.086 \\
\multirow{2}{*}{ NC-W } & Numerical coupled solution with & TCE & 6.0 & 0.069 \\
& fluid withdrawal; Section 3.3 & Toluene & 5.5 & 0.055 \\
\hline
\end{tabular}

$\frac{\partial C_{0}^{w}(\xi=1, t)}{\partial \xi}=0$

No exact analytical solutions exist for the resulting moving boundary diffusion problem given by Eqs. (16) through (19), sometimes referred to as a Stefan problem (Stefan, 1889) in the heat transfer and diffusion literature (Ockendon and Hodgkings, 1975; Crank, 1984; Tarzia, 2000). We solved the moving boundary problem numerically using the NDSolve subroutine from the Mathematica Software (Wolfram, 2009).

\section{Results and discussion}

\subsection{VOC concentration in the air phase and water phases}

Fig. 2 depicts the normalized concentration $\left(C^{a} / C_{\max }^{a}\right)$ of the two VOCs as a function of time, where $C^{a}$ denotes the observed concentration of the target compound in air at a given time and $C_{\max }^{a}$ is the maximum concentration of the target compound in air (corresponding to its vapor pressure). Results show that the air phase concentrations of both TCE and toluene increased relatively quickly to their maximum values and then remained constant. The evaporation rates of TCE and toluene were very similar, leading to almost identical concentration distributions versus time. This is because both the vapor pressures and diffusion coefficients of TCE and toluene in air are very similar (Table 1 ).

Fig. 3 shows normalized concentrations $\left(C^{w} / C_{\max }^{w}\right)$ of TCE and toluene in the unstirred water as a function of time, where $C^{w}$ denotes the observed VOC concentration in the water phase and $C_{\max }^{w}$ is the maximum concentration of the VOC in water $\left(=S^{w}\right.$ : solubility). The data indicate that the dissolution rate of TCE vapor into water is slightly faster as compared to toluene vapor. The results in Fig. 3 for the unstirred experiments show a significant difference between the dissolution rate in water as compared to the evaporation rates into air (Fig. 2). Molecular diffusion within the water reservoir away from the air-water interface clearly acted as a barrier for effective mass transfer from the air phase into the water phase. To investigate this effect, we used a magnetic stirrer eliminate VOC diffusion within the water phase. Fig. 4 depicts normalized concentrations of TCE as a function of time for different stirring speeds. The results show that stirring the water reservoir caused a quick increase in the TCE concentrations. The data in Fig. 4 show that an increase in the stirring speed from 100 to $300 \mathrm{rmp}$ had minimal effect on the TCE concentration distributions in the water reservoir.

\subsection{Salinity and $p H$ effects on the dissolution of VOC vapors in water}

Dissolved salts in the water phase can have an important effect on the partitioning behavior of VOCs between the air and water phases. Fig. 5 shows normalized concentrations of TCE and toluene as a function of time for both DI water and seawater. The normalized concentrations in Fig. 5 were plotted relative to the solubility VOC concentrations of DI water. Results indicate that salinity has a significant effect on especially the solubility $\left(S^{w}\right)$ of TCE, which decreased by about $30 \%$ for seawater as compared to DI water. This is in line with previous studies (e.g., Schwarzenbach et al., 2003) showing that at moderate salt concentrations typical for seawater $(\sim 0.5 \mathrm{M})$, salinity will affect the aqueous solubility by a factor of between less than 1.5 for small and/or polar compounds to about 3 for large, nonpolar compounds. Our experiments further showed relatively small effects on the rates of mass transfer of TCE and toluene across the air-water interfaces (see also Supplemental Fig. 1s). The rate of mass transfer into seawater for TCE was slightly higher than for Toluene. Our findings are consistent with a previous study by Ramus et al. (2012) showing that moderate salinities ( $\leq 1 \mathrm{M})$ will have relatively small effects on the mass transfer of VOCs across air-water interfaces. We further estimated Henry's constants of TCE and toluene dissolving in seawater. Henry's constants of both TCE and toluene decreased to $69 \%$ and $70 \%$, respectively, of the values for DI water.

Fig. 2s (Supplementary Material) depicts normalized concentrations $\left(C^{w} / S^{w}\right)$ of TCE and toluene as a function of time for various $\mathrm{pH}$ values $(2$, 7 , and 12) of the water reservoir. Results show that dissolution of VOC vapors into water is essentially independent of $\mathrm{pH}$. Hence, $\mathrm{pH}$ cannot be a limiting factor for the dissolution kinetics of these two VOCs. However, we note that the literature shows that the solubility of the chlorinated solvents (e.g., TCE) is considerably increased by biosurfactants at $\mathrm{pH}$ values less than 7 (Albino and Nambi, 2009).

\subsection{Approximate kinetic analysis of the stirred experiments}

We first analyzed the data using the approximate decoupled analytical solution (referred to as AD) given by Eqs. (5a) and (5b) to estimate the dissolution $\left(k^{d}\right)$ rate coefficient of the two VOCs. Fig. 6 shows plots of $\ln \left[\left(C_{\max }^{w}-C^{w}\right) / C_{\max }^{w}\right]$ vs. time for both TCE and toluene dissolution into water, consistent with Eq. (5b). Results confirm that dissolution followed a first-order rate process. Values of the coefficient of determination $\left(R^{2}\right)$ of the semi-log regressions obtained for TCE and toluene were in most or all cases equal to 0.98 or higher. The corresponding dissolution rate constants $\left(k^{d}\right)$ are given in Table 2 . Results indicate that the

\section{$V^{w}$ variable with time}

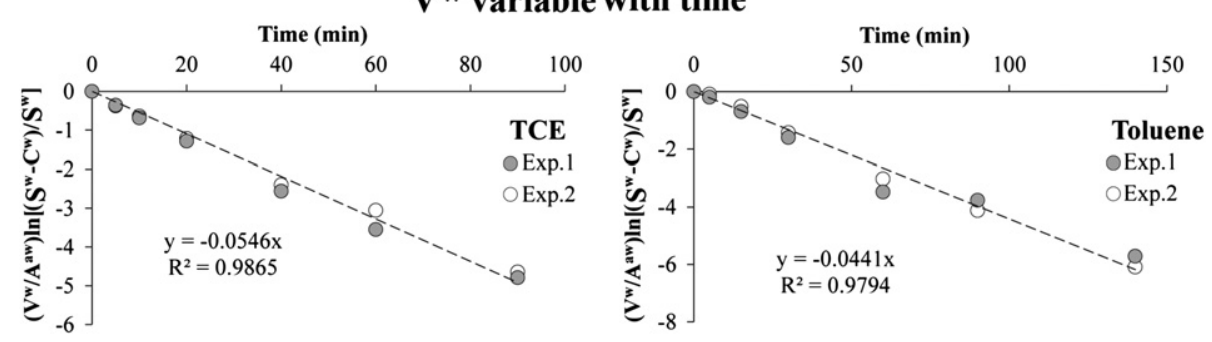

Fig. 7. Plots of $V^{w}(t) / A^{a w} \ln \left[\left(S^{w}-C^{w}\right) / S^{w}\right]$ vs. time corresponding to Eqs. (5a) and (5b) assuming time-variable values of $V^{a}(t)$ and $V^{w}(t)$. 

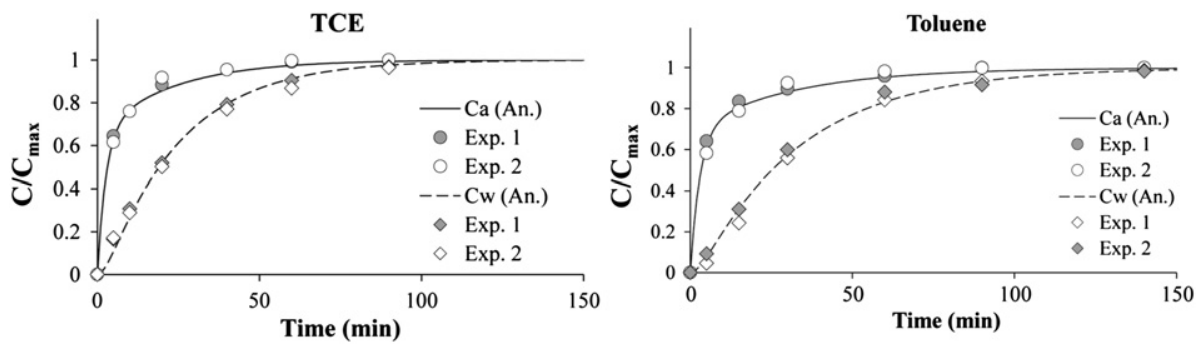

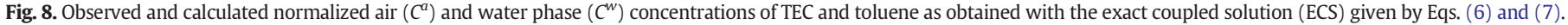

dissolution rate constant $\left(k^{d}\right)$ for TCE was slightly larger as compared to the value for toluene.

The results in Fig. 6 were obtained using the approximate decoupled analytical solutions neglecting the effect of withdrawal of fluid due to sampling. Fig. 7 gives similar results when fluid withdrawal is taken into account $(\mathrm{AD}-\mathrm{W})$. The regressions in Fig. 7 are very similar to those in Fig. 6, except that the fitted $k^{d}$ values are about 25\% smaller. These small differences in the rate constants were expected since the volume of the water reservoir $\left(V^{w}\right)$ slowly decreased, thus requiring a slightly slower rate of dissolution to reach similar concentrations in the water reservoir. We will show in the following section that the differences are actually relatively small and probably can be neglected in experiments where the reductions in liquid volume are less than about 20 to $40 \%$ of the original volume (in our stirred experiments the volume of the water reservoir decreased from $25 \mathrm{ml}$ to $16 \mathrm{ml}$ ).

\subsection{Full analytic solution of the stirred experiments}

The results in Figs. 6 and 7 were obtained assuming the fully decoupled analytical solution (AD and AD-W) for the VOC concentrations of the water phases as given by Eqs. (5a) and (10), respectively. Fig. 8 shows the fitted solutions using the exact analytical solution (EC) assuming coupled air and water phases, i.e., using Eqs. (6) and (7) for $C^{a}(t)$ and $C^{w}(t)$, respectively. A sequential iterative fitting process was used in which $k^{e}$ was fitted first to the $C^{a}$ data, followed by fitting $k^{d}$ to the $C^{w}$ data using the fitted value of $k^{e}$ as a known parameter. The $k^{e}$ fitting processes continued by using the fitted value of $k^{d}$, etc., until convergence was reached where the optimized $k^{e}$ and $k^{d}$ values did not change anymore. $R^{2}$ values of the separate $C^{a}(t)$ and $C^{w}(t)$ optimizations where 0.999 and 0.997 , respectively for TCE, and 0.999 and 0.998 for toluene, thus reflecting very close matches with the data as shown also by the close fits of the TCE and toluene data in Fig. 8.

Fitted values of the rate coefficients using the complete coupled exact solution are listed in Table 2. Values of $k^{d}$ for the coupled solutions for TCE and toluene were about $60 \%$ higher than those estimated with the decoupled solutions. These results are important in that they indicate that decoupling the air- and water-phase solutions can lead to significantly different (lower) values of the dissolution rate coefficients. Accounting for the effects of fluid withdrawal also affected the estimates of $k^{d}$, but they were less dramatic then those caused by decoupling the air and water phase VOC solutions (Table 2).

The differences between the various formulations are further demonstrated in Fig. 9, which shows results obtained with the different models using the $k^{e}$ and $k^{d}$ values estimated with the coupled exact solution. The plots include the approximate decoupled analytical solutions without (AD) and with (AD-W) sampling fluid withdrawal, the exact coupled analytical solution (EC) without fluid withdrawal, and the numerical coupled solution with fluid withdrawal (NC-W). The plots indicate that decoupling the air phase and fluid phase solutions (e.g., AD versus EC) leads to inaccurate results, while the effects of fluid withdrawal are far less significant (e.g., AD versus AD-W). Still, the withdrawal of fluid from the water reservoir does have a noticeable effect on the calculated VOC distributions in the water reservoir. Our results hence suggest that sample withdrawal should be limited as much as possible relative to the available total amount of water in the experimental setup.

Also, one interesting result of the modeling analysis is that the calculated decoupled (AD-W) distributions with fluid withdrawal are not continuous versus time due to discontinuity in the water volumes versus time as given by Eqs. (9) and (10). These discontinuities, however, are relatively small and barely visible on the AD-W plots in Fig. 9, and as such probably can be ignored in the analyses of many or most
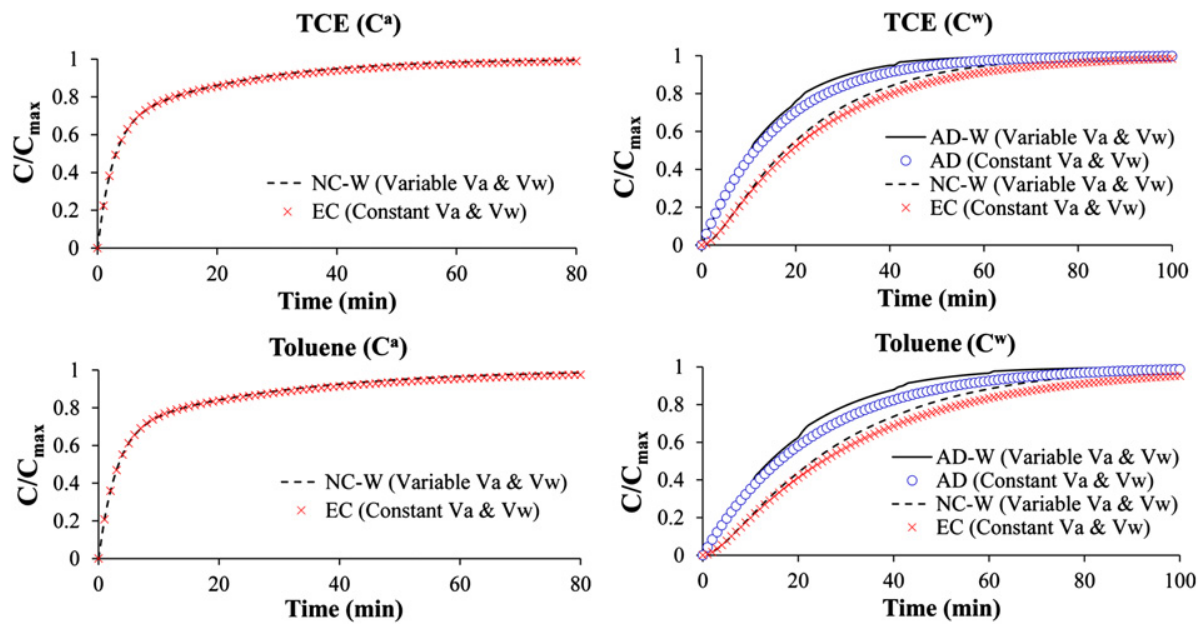

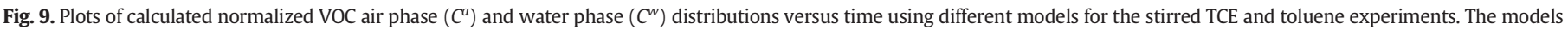

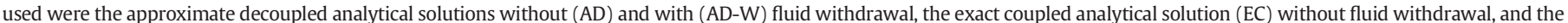
numerical coupled solution (NC-W) with fluid withdrawal. 
experiments. Please note, however, that no discontinuities occur in the coupled numerical solutions for the case with fluid withdrawal (NC-W).

\subsection{Analysis of the unstirred experiments}

Finally, Fig. 3 gave results for the unstirred VOC dissolution/diffusion experiments. Included in the figure are predictions obtained with the moving boundary numerical solution in Section 3.4. The numerical results were obtained assuming that VOC concentrations in the headspace remained constant in time at their maximum values corresponding to their vapor pressures (i.e., $C_{\max }^{a}$ ). This approach restricts the analysis to only the water reservoir, and thus allowed us to fix the coefficient $\mu$ in Eq. (13) at zero. Values of the various parameters used in the calculations are given in Table 1.

The plots in Fig. 3 show observed and calculated TCE and toluene concentration values at the sampling point $0.8 \mathrm{~cm}$ from the bottom, i.e., at $x=L(t)-0.8$. As indicated by the plots, simulation results using known values of the VOC molecular diffusion coefficients $\left(D^{w}\right)$ in water showed significant discrepancies with the experimental data (Mod. 1 in Fig. 3). However, when we used in our simulations effective VOC molecular diffusion coefficients that were three times the known values $\left(3 \times D^{w}\right)$, relatively good agreement resulted with the observed data (Mod. 2). We believe that the withdrawal of water during sampling, even if done very carefully, may have caused some minor convection of the fluid within the reservoir. Even if extremely small, these effects macroscopically will quickly overshadow pure liquid diffusion within the water reservoir. Rather than using a reservoir filled with water, perhaps experiments with a saturated porous medium in the reservoir (e.g., with very coarse sand or glass beads) could have minimized these type of fluid convection processes due to sampling.

\section{Conclusions}

In this study we performed a series of batch experiments to investigate the kinetics of TCE and toluene vapors into both stirred and unstirred water reservoirs at room temperature $\left(21 \pm 1{ }^{\circ} \mathrm{C}\right)$. The effects of $\mathrm{pH}$ and especially salinity on the dissolution of TCE and toluene vapors in water were investigated. We also evaluated the effects of molecular diffusion on mass transfer across the air-water interfaces using stirred and unstirred water reservoir experiments. We further evaluated the evaporation kinetics of the two VOC compounds in the headspace above the water reservoir.

VOC vapor dissolution in the water phase was found to be independent of $\mathrm{pH}$. However, salinity was found to have an important effect on dissolution, mass transfer rates as well as the solubility of TCE and toluene into water. The maximum concentrations of two compounds, corresponding to their solubilities, decreased by about $30 \%$ in seawater as compared to DI water. Henry's law constants of both TCE and toluene hence were also about $30 \%$ less in seawater. This shows that salinity can be a limiting factor for VOC mass transfer across air-water interfaces.

Results of the stirred water experiments revealed a quick increase in the VOC concentrations with time since molecular diffusion was eliminated as a possible barrier for VOC transfer ways from the air-water interface. Stirring speed had only a small effect on the VOC concentrations in the water phase. Dissolution of the VOC vapors from the headspace into the water reservoir was found to follow first-order kinetics.

Several models were used to analyze the water phase VOC concentrations. The data could be described equally well using approximate analytical solutions that decoupled the VOC concentration dynamics in the water phases from those in the air phase, as well more complete coupled solutions. However, the estimated dissolution rate constants $\left(k^{d}\right)$ were quite different for the various formulations, including for models that accounted for fluid withdrawal from the water reservoir during sampling. Decoupling VOC air and water phase mass transfer processes produced especially unreliable estimate of $k^{d}$, whereas the effects of fluid withdrawal on the rate coefficients were far less dramatic.
Results for the undisturbed (unstirred) water reservoir showed a very slow rise of the VOC concentrations in the water phase with time. A significant difference existed between the dissolution rate of VOC vapors into the undisturbed water and the VOC evaporation rates in air above the reservoir. Simulations of VOC transport in undisturbed water using a moving boundary value model that accounted for fluid withdrawal showed a significant discrepancy between experimental data and simulation results when know values for the VOC molecular diffusion coefficients $\left(D^{w}\right)$ were used. An artificial increase in the VOC molecular diffusion $\left(3 \times D^{w}\right)$ could satisfactorily simulate the experimental data, presumably because of some convection in the water reservoir caused by the sampling process

\section{Acknowledgements}

This work was supported in part by Veni Research Program Project no. 016.151.047, which is financed by the Netherlands Organisation for Scientific Research (NWO). S. Majid Hassanizadeh received funding from the European Research Council under the European Union's Seventh Framework Programme (FP/2007-566 2013)/ERC Grant Agreement no. 341225 . The comments by anonymous reviewers further helped to improve the manuscript.

\section{Appendix A. Supplementary data}

Supplementary data to this article can be found online at http://dx. doi.org/10.1016/j.jconhyd.2016.12.004.

\section{References}

Albino, J.D., Nambi, I.M., 2009. Effect of biosurfactants on the aqueous solubility of PCE and TCE. J. Environ. Sci. Health, Part A. Toxic Hazard. Subst. Environ. Eng. 44 (14), 1565-1573.

Almeida, C.M.M., Boas, L.V., 2004. Analysis of BTEX and other substituted benzenes in water using headspace SPME-GC-FID: method validation. J. Environ. Monit. 6, 80-88.

Aumont, B., Madronich, S., Bey, I., Tyndall, G.S., 2000. Contribution of secondary VOC to the composition of aqueous atmospheric particles: a modeling approach. J. Atmos. Chem. 35, 59-75.

Berscheid, M., Burger, K., Hutchison, N., Muniz-Ghazi, H., Renzi, B., Ruttan, P., Sterling, S. 2010. Proven Technologies and Remedies Guidance. Remediation of Chlorinated Volatile Organic Compounds in Vadose Zone Soil. California Department of Toxic Substances Control (154 pp).

Boris, A.J., Desyaterik, Y., Collett Jr., J.L., 2014. How do components of real cloud water affect aqueous pyruvate oxidation? Atmos. Res. 143, 95-106.

Bowen, W.R., Yousef, H.N.S., 2003. Effect of salts on water viscosity in narrow membrane pores. J. Colloid Interface Sci. 264 (2), 452-457.

Chawla, R.C., Doura, K.F., McKay, D., 2001. Effect of alcohol cosolvents on the aqueous solubility of trichloroethylene. Proc. 2001 Conf. on Environmental Research; New Approaches to Managing Environmental Quality in the Heartland. May 21-24, Kansas State Univ., Manhattan, KS . https://www.engg.ksu.edu/HSRC/01Proceed/docs/52.pdf.

Crank, J., 1984. Free and Moving Boundary Problems. Clarendon Press, Oxford.

Endo, S., Pfennigsdorff, A., Goss, K.U., 2012. Salting-out effect in aqueous NaCl solutions: trends with size and polarity of solute molecules. Environ. Sci. Technol. 46, 1496-1503.

Ervens, B., Volkamer, R., 2010. Glyoxal processing by aerosol multiphase chemistry: towards a kinetic modeling framework of secondary organic aerosol formation in aqueous particles. Atmos. Chem. Phys. 10, 8219-8244.

Estivill, I.S., Hargreaves, D.M., Puma, G.L., 2007. Evaluation of the intrinsic photocatalytic oxidation kinetics of indoor air pollutants. Environ. Sci. Technol. 41 (6), 2028-2035.

Falabella, J.B., Teja, A.S., 2008. Air-water partitioning of gasoline components in the presence of sodium chloride. Energy \& Fuels 22 (1), 398-401.

Görgényi, M., Dewulf, J., Van Langenhove, H., Király, Z., 2005. Solubility of volatile organic compounds in aqueous ammonia solution. Chemosphere 59 (8), 1083-1090.

Han, L., Qian, L., Yan, J., Liu, R., Du, Y., Chen, M., 2016. A comparison of risk modeling tools and a case study for human health risk assessment of volatile organic compounds in contaminated groundwater. Environ. Sci. Pollut. R. 23 (2), 1234-1245.

Hers, I., Atwater, J., Li, L., Gilje, R.Z., 2000. Evaluation of vadose zone biodegradation of BTX vapours. J. Contam. Hydrol. 46, 233-264.

Kubinec, R., Adamuscin, J., Jurdakova, H., Foltin, M., Ostrovsky, I., Kraus, A., Sojak, L., 2005 Gas chromatographic determination of benzene, toluene, ethylbenzene and xylenes using flame ionization detector in water samples with direct aqueous injection up to $250 \mu \mathrm{l}$. J. Chromatogr. A 1084, 90-94.

Lewis, S., Lynch, A., Bachas, L., Hampson, S., Ormsbee, L., Bhattacharyya, D., 2009. Chelatemodified Fenton reaction for the degradation of trichloroethylene in aqueous and two-phase systems. Environ. Eng. Sci. 26 (4), 849-859. 
Mahmoodlu, M.G., Hartog, N., Hassanizadeh, S.M., Raoof, A., 2013. Oxidation of volatile organic vapours in air by solid potassium permanganate. Chemosphere 91 (11), $1534-1538$

Mahmoodlu, M.G., Hassanizadeh, S.M., Hartog, N., Raoof, A., 2014. Oxidation of trichloroethylene, toluene, and ethanol vapors by a partially saturated permeable reactive barrier. J. Contam. Hydrol. 164, 193-208.

Mahmoodlu, M.G., Hassanizadeh, S.M., Hartog, N., Raoof, A., van Genuchten, M.T., 2015 Evaluation of a horizontal permeable reactive barrier for preventing upward diffusion of volatile organic compounds through the unsaturated zone. J. Environ. Manag. 163, 204-213.

Ockendon, J.R., Hodgkings, W.R (Eds.), 1975. Moving boundary problems in heat flow and diffusion. Proc. Oxford Conf., March 1974. Clarendon Press.

Peng, M., Vane, L.M., Liu, S.X., 2003. Recent advances in VOCs removal from water by pervaporation. J. Hazard. Mater. 98 (1), 69-90.

Przyjazny, A., Kokosa, J.M., 2002. Analytical characteristics of the determination of benzene, toluene, ethylbenzene and xylenes in water by headspace solvent microextraction. J. Chromatogr. A 977 (2), 143-153.

Ramus, K., Kopinke, F.D., Georgi, A., 2012. Influence of dissolved humic substances on the mass transfer of organic compounds across the air-water interface. Chemosphere 86, $138-143$.

Rivett, M.O., Wealthall, G.P., Dearden, R.A., McAlary, T.A., 2011. Review of unsaturatedzone transport and attenuation of volatile organic compound (VOC) plumes leached from shallow source zones. J. Contam. Hydrol. 123, 130-156.

Schubert, M., Schmidt, A., Müller, K., Weiss, H., 2011. Using radon-222 as indicator for the evaluation of the efficiency of groundwater remediation by in-situ air sparging. Environ. Radioact. 102, 193-199.

Schwarzenbach, R.P., Gschwend, P.M., Imboden, D.M., 2003. Environmental Geochemistry. John Wiley \& Sons, Inc
Sieg, K., Fries, E., Püttmann, W., 2008. Analysis of benzene, toluene, ethylbenzene, xylenes and n-aldehydes in melted snow water via solid-phase dynamic extraction combined with gas chromatography/mass spectrometry. J. Chromatogr. A 1178 (1-2), 178-186.

Sleep, B.E., Sykes, J.F., 1989. Modeling the transport of volatile organics in variably saturated media. Water Resour. Res. 25 (1), 81-92.

Snow, N.H., 2002. Head-space analysis in modern gas chromatography. Trace-Trend Anal. Chem. 21, 608-617.

Stefan, J., 1889. Über einige Probleme der Theory der Wärmeleitung. S.-B. Wien. Akad. Mat. Natur. 98, 473-484

Tarzia, D.A., 2000. A bibliography on moving-free boundary problems or the heatdiffusion equation. The Stefan and related problems. MAT Ser. A, No. 2. Austral Univ., Rosario, Argentina.

USEPA (U.S. Environmental Protection Agency), 1991. Dense non-aqueous phase liquid. Ground Water Issue. EPA/540/4-91-002. www.epa.gov/superfund/remedytech/tsp/ downl-oad/issue8.pdf.

Vane, L.M., Giroux, E.L., 2000. Henry's law constants and micellar partitioning of volatile organic compounds in surfactant solutions. J. Chem. Eng. Data 45 (1), 38-47.

Wolfram Research, Inc., 2009. Mathematica, Version 7.0, Champaign, IL

Yap, C.L., Gan, S., Ng, H.K., 2012. Evaluation of solubility of polycyclic aromatic hydrocarbons in ethyl lactate/water versus ethanol/water mixtures for contaminated soil remediation applications. J. Environ. Sci. 24 (6), 1064-1075.

Yoshii, T, Niibori, Y, Mimura, H. 2012. Some fundamental experiments on apparent dissolution rate of gas phase in the groundwater recovery processes of the geological disposal system. WM2012 Conf., Feb. 26-March 1, Phoenix, AZ, USA. 